\title{
Communicative-Associative Transition to Smart Artificial Intelligence by Criteria with Help of Ensembles of Diversified Agents
}

\author{
Evgeniy Bryndin', Irina Bryndina ${ }^{2}$ \\ ${ }^{1,2}$ Research Department, Research Center "NATURAL INFORMATICS," Novosibirsk, Rusia \\ iriska26@ngs.ru
}

\begin{abstract}
Cognitive virtual smart artificial intelligence can be formed by ensembles of diversified agents with strong artificial intelligence based on communicative-associative logic by recurring development of professional skills, increasing visual, sound, and subject, spatial and temporal sensitivity. Several diversifiable agents that try to get the same conclusion will give a more accurate result, so several diversifiable agents are combined into an ensemble. Then, based on the criteria of utility and preference, the final result is obtained based on the conclusions of diversifying agents. This approach increases accuracy. Bagging and boosting techniques are used to form ensembles. Bagging is a combination of independent diversifiable agents by averaging patterns (weighted average, majority vote, or normal average). Boosting is the construction of ensembles of diversifiable agents consistently. The idea here is that the next agent will consider the errors of the previous agent. Due to the fact that diversifiable agents take into account errors committed by previous agents, it takes less time to get to a real response. The combination of Bagging and Boosting decision-making methods allows the development of intelligent artificial intelligence by ensembles of diversified agents. Cognitive virtual smart artificial intelligence becomes smarter through the accumulated professional experience of high-tech skills, competencies and knowledge, having increased visual, sound, subject, spatial and temporal sensitivity. Standardization of strong artificial intelligence and the use of ensembles of intelligent compatible diversified agents will help to find boundaries in which smart artificial intelligence will benefit humanity and not harm.
\end{abstract}

Keywords: smart artificial intelligence; communicative associative logic; preference and utility criteria; ensembles of diversified agents

\section{Introduction}

Microsoft has developed a new supercomputer based on the Azure cloud in collaboration and exclusive to OpenAI, a research organization founded by Elon Musk and Sam Altman. Supercomputer is designed to develop a new generation of AI models that are more flexible and capable of solving different problems at the same time. Tools for responsible use of machine learning have been added to the Azure Machine Learning service. They will allow you to control and correct problems with neural networks. In addition, the tools will allow you to understand exactly how algorithms work and control data privacy. They are available both as part of Azure Machine Learning and in the public domain. Project Cortex's new service uses machine learning and Microsoft Graph to create a "knowledge network" in which information will be collected from Microsoft 365 and external sources. This allows you to automate workflows and better manage companies. Microsoft Lists allows you to create lists, track the status of tasks, and share information with colleagues. We are talking about the appearance of smart artificial intelligence. Smart artificial intelligence differs from strong artificial intelligence in that it is able to learn and perform various tasks and make decisions on its own [1-3]. It looks more like a person, but works at the speed of the fastest computers. The author of the article proposes to develop smart artificial intelligence based on communicative-associative logic, hierarchical preferences, evolving utility, ensembles of diversified agents. 


\section{Review of Literatures}

\subsection{Communicative Associative Logic of Technological Smart Artificial Intelligence}

The thought of man in essence is the spirit of reason. The mind knows everything in comparison. He compares heard and written thoughts, opinions and worldviews of other people.

If your own thoughts, opinions, images and worldviews coincide with other people, then consent comes.

If the mind does not agree with the thoughts, opinions, images and worldviews of other people, then the mind forms its own thoughts, opinions, images and worldviews.

Technological smart artificial intelligence can compare thoughts, opinions, images and worldviews according to utility criteria.

Technological smart artificial intelligence can choose thoughts, opinions, images and worldviews according to the criterion of preference.

Technological smart artificial intelligence can detect novelty on the principle of opposite (optimal - not optimal; effective - not effective; dangerous - safe, etc.) method from nasty based on objective conditions based on communicative associative logic.

\subsection{Entity Dictionary}

Let $\mathrm{S}$ be a spelling dictionary, where $\mathrm{S}=\{\mathrm{Si}\}, \mathrm{Si}$ is a morphological word. The word $\mathrm{Si}$ refers to the Qij feature of the Mij representative from the Mi set, where $\mathrm{Mi}=\{\mathrm{Mij}\}$. Denote the lexical meaning of the word $\mathrm{Si}$ via $\{\mathrm{Mij}, \mathrm{Qij}, \mathrm{Si}\}$. The relationship of the lexical values of words $\{\mathrm{Si}\}$ with elements of the set $\mathrm{Mi}$ is given by the set of feature relations Qi, where Qi $=\{\mathrm{Qij},(\mathrm{Mi}, \mathrm{Mij})\}$.

A set of lexical values associated with a set of characteristic relations with representatives is an essential dictionary. Words in the dictionary are supplied with characteristic indexes according to their characteristic relationships with representatives. The entity dictionary captures the characteristic entities of representatives. The dictionary helps to use words with its lexical meaning and distinguish between representatives whom they call on a symbolic level.

Words are used based on characteristic indices. Each feature has three indexes. One index indicates the subject area of knowledge, the second indicates the situation, the third indicates the situational moment. Words with multiple lexical meanings have multiple sets of indexes. For example, flour and flour. The word field is used in various subject areas. Each set of indexes defines a lexical word value.

\subsection{Information Needs Technology}

Tasks, problems, tasks and goals are formed in the form of information needs. The text of the information requirement is based on the functional natural language from the elements of the essential dictionary. Functional natural language describes communicative and associative relationships between knowledge elements. Communicative and associative language relationships between knowledge elements follow the relationships of objects, actions, qualities, properties, time, space, etc., which we denote knowledge elements. 
The language links the structural, functional and semantic attributes of knowledge elements. The use of words as part of information demand knowledge elements is defined by communicative links. The language has grammatical rules for the speciation of word forms for the creation and expansion of families and the creation of communities, communicative rules for the formation of phrases, sentences of judgments. Each rule has its own definition area. For example, in a deductive generalization rule, the domain of the definition is deductive sets. Deductive rules allow you to organize language words into generalized sets. The generalized set is represented by a convergent feature. The private values of the convergent characteristic are its specificity. In the language, the emphasis in the word, in the sentence, in the judgment between sentences is fixed by synthactics. The impact words in the sentence are shown in bold. For example, I was in China or I was in China or I was in China. Impact syllables are shown in bold. Communicative relationships of content sentences have syntactic notations.

According to the act, ascending parsing and morphological analysis identifies sentences of information need that correspond to acts of thinking and establishes grammatical types and characteristics for each word according to a dictionary of semantic orientation, builds a tree of syntactic subordination of words, determines the communicative relationship of words, phrases and sentences. For analysis, you use an essential dictionary, networks of phrases, sentences, judgments, information families, and communities.

Parsing is carried out by language syntax markup of information demand and its structural situational-characteristic markup. By parsing, the grammatical values of knowledge elements are determined, words in sentences, phrases in sentences, sentences in judgments, elementary judgments in composite judgments are distinguished, grammatical types of words, species groups of phrases according to grammatical types of words of basics and additional, grammatical types of lexical values of information niches of sentences, and species relationships of sentences of elementary judgments are identified.

Morphological analysis is carried out according to linguistic morphological markup and schematic situational-characteristic. In the process of morphological analysis, morphological values of knowledge elements and situational-characteristic schemes of morphological values are determined.

The selection of sentences is carried out according to a syntactic structure, in which words are assigned features and indexes of representatives, grammatical types and lexical values, semantic values to phrases. The information niches of the quotation are determined by the act-based upstream parsing and morphological analysis of the information demand texts. The resulting text, after an act analysis, enters the system of symbolic and linguistic implementation of information needs - a system of imitation of thinking.

The input information of the system is the information demand and attributes obtained in the process of syntactic and morphological analysis. According to information obtained as a result of syntactic and morphological analysis of information demand, the system of imitation of thinking carries out its semantic analysis.

The information requirement type is first recognized. The information need may be questionable or prompting. Semantic analysis then determines whether there is an implementation of the knowledge base information requirement. If it is not implemented, it is determined whether the information requirement is a typical baseline. If the information requirement is not a generic basic requirement, the analysis determines whether it consists of a generic basic information requirement. If it does not consist of generic basic information needs, semantic analysis determines whether there is a necessary and sufficient set of implementation procedures in the knowledge base and a necessary and sufficient set of knowledge elements in the knowledge base to implement it.

If, as a result of analysis, it turns out that in the knowledge base there are elements for realizing the information need, then the simulation system of thinking forms the implementation of the information need from the knowledge elements of the information need 
and the knowledge elements for implementation from the knowledge base. By marking the text of the information demand, the system determines pointers to the necessary sets of knowledge elements in the knowledge base in the subject area specified by the user, and to the implementation procedures in the skill base, and determines the implementation scheme according to the type and layout of the need.

The markup indicates the attributes of knowledge elements: schematic, characteristic, and grammatical (syntactic, morphological), semantic and lexical.

Pointers to knowledge and implementation elements are formed through an information receptive field. The information receptive field contains information connections with inputs of a network of phrases, sentences, judgments, as well as with implementations of typical basic information needs. It contains instructions on the necessary and sufficient set of implementation procedures for each lexical value of the information action and on the necessary and sufficient set of knowledge elements for each implementation procedure, as well as information links with implementation procedures stored in the skills base.

Markup of information demand and user-defined area of knowledge is used to define pointers to find necessary and sufficient set of implementation elements in the knowledge base, necessary and sufficient set of knowledge elements in the knowledge base, schemes and structures of formation of new phrases, sentences, judgments.

The system of simulation of thinking starts the procedure of building a network of element-by-element realization of information demand from the necessary and sufficient set of knowledge elements and implementation procedures. It builds a network of element-byelement implementation of information needs in databases of knowledge and skills. It then performs initial markup of knowledge elements and implementation procedures and their relationships. Markup defines the characteristic participation of words in phrases, the situational-characteristic participation of phrases in sentences and the situational participation of sentences in judgments.

After marking the element-by-element implementation network, it is launched to realize the information demand.

Information needs are considered feasible if the syntax structure of the implementation, lexical and semantic values of the components, as well as implementation procedures are determined.

If the input information requirement is a combination of typical information requirements or a valid modification thereof, it is realizable.

A typical incentive information requirement consists of an information action and an information condition. If the information need is prompted, then it explicitly indicates the action.

If the information requirement or the information requirement realization contains an information action, then the standard realization procedure is started. Reference to implementation procedure is indicated in information action markup.

For example, let the imperative information need be given "to find the sum of $\mathrm{X}$ plus $\mathrm{Y}$, with $\mathrm{X}$ equal to $15, \mathrm{Y}$ equal to 10 (Figure 1 ). $\mathrm{X}$ is $15, \mathrm{Y}$ is 10 is an information condition. The communicative phrases "X equals" and "equals 15" in the information condition of the information action "plus" initiates the replacement of $X$ with 15. According to the information condition "X equals 15, Y equals 10," X will be replaced by 15 , and $\mathrm{Y}$ by 10 in the typical implementation of the information demand. The lexical value of the informational action "plus" in the essential symbolic language dictionary contains a reference to the analytical sign "+" in the analytical entity dictionary. The sign " $+"$ in the analytical entity dictionary refers to the typical procedure for adding two arguments. 


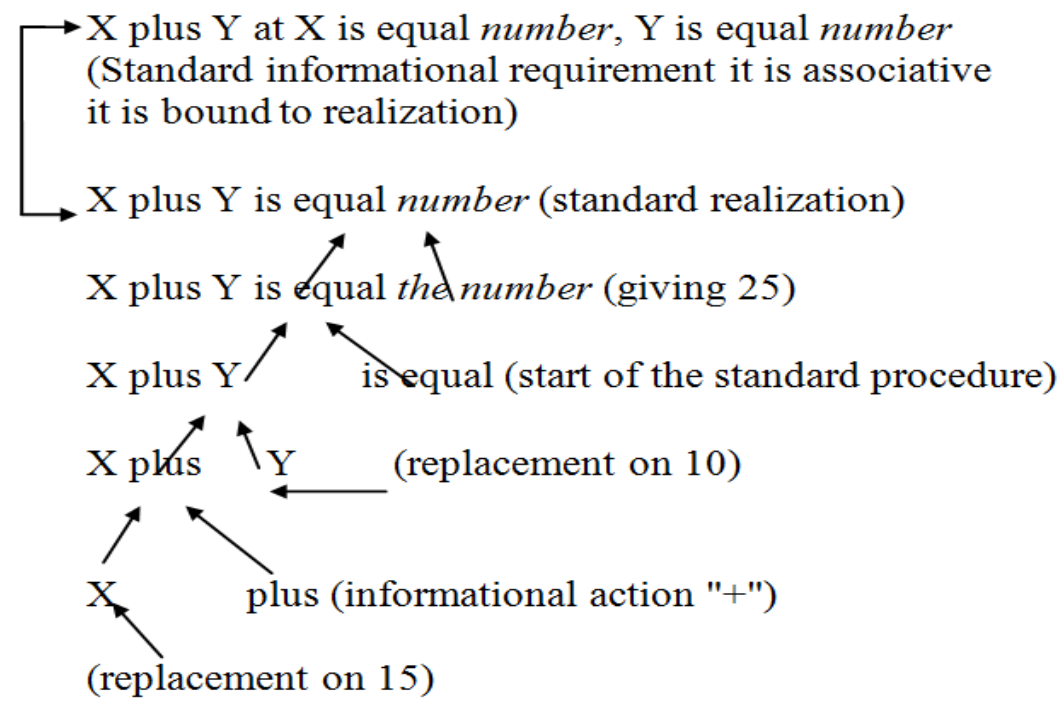

Figure 1. Network Structure of Addition

The question information need is a question proposal. If the information need is questionable, it explicitly indicates the question phrase defining the direction of implementation.

The implementation of the question information need is built either in the network of proposals or in the network of judgments. In networks, the semantic value of the realization of the need is revealed, either in the form of a proposal or judgment.

After implementation, the new information need is entered into the knowledge base and linked to the knowledge element, which is its implementation.

The technology of implementing the communicative-associative logic of imitation thinking allows you to develop interactive educational systems of a natural language level in various subjects in the educational space. The subject area of knowledge is presented in the form of a communicative-associative network of information needs and their implementations, consisting of elements of knowledge. Communicative phrases form sentences, communicative sentences form judgments. The association between the information need and its implementation is associative.

For example, let the imperative information need "Formulate Pythagorean theorem" be given (Figure 2). By the lexical meaning of the word "formulation," we find through the essential dictionary the representative phrase "formulation of the theorem" in the network of the subject area of knowledge indicated in the markup of information need. Then, through the tree of communicative phrases with lexical values of information demand, by synthesizing them, we get to the associative vertex "the formulation of the Pythagorean theorem. Further, along the associative connection from the associative vertex of the information need, we move to the associative vertex of the implementation "the square of the hypotenuse is equal to the sum of the squares of the catets. 


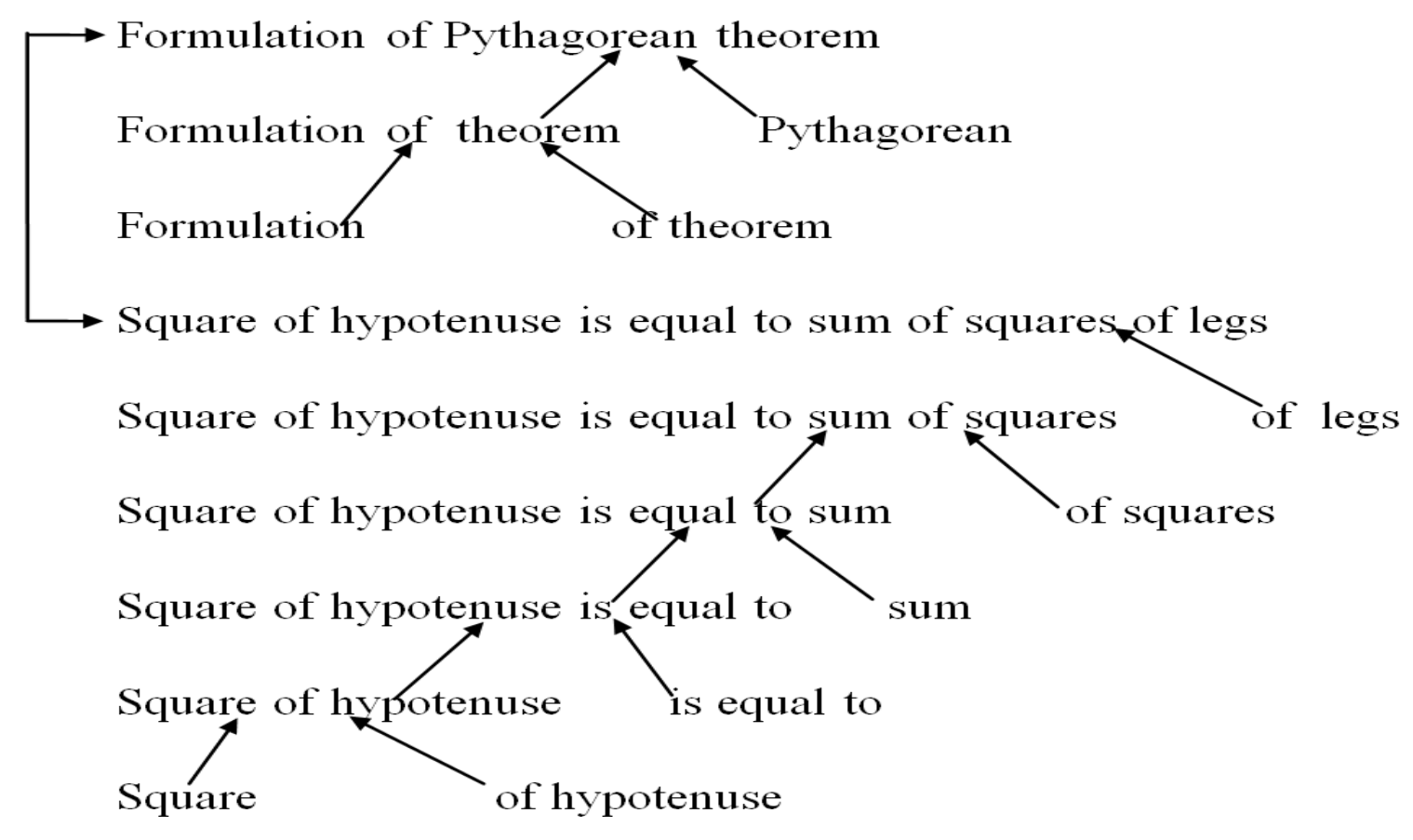

Figure 2. Associative Communicative Network of Pythagorean Theorem

The realization of an information requirement can itself be an information requirement. In this case, by the communicative tree of the lexical values of the theorem, we get to the associative vertex by synthesizing them. Then, by associative connection, we determine the implementation of the "Formulation of Pythagorean theorem"

The words of information demand have markup indicating either a lexical value, or a computational procedure, or a behavioral procedure. For example, the word "add" can be a lexical value, either an arithmetic action or a behavioral action (add cubes). For judgments, the subject area and situation are indicated. For quotations, you specify the situational moment and the characteristics of the lexical values. The reflection of the semantics of subject knowledge is carried out using a symbolic-linguistic sign system based on communicativeassociative logic and subject-situational-characteristic relations of entities of reality and abstraction objects with knowledge elements of the essential dictionary.

The information demand implementation system uses a knowledge base and a skill base. The implementation of the information demand is taken either from the knowledge base, or is developed by a typical procedure for implementing the skills base according to the current information demand, or a network of element-by-element implementation according to the combined information demand is formed. Schemes for implementing information needs are obtained from a study of educational practices in the formation of imitative thinking. The diagrams are shown in Figures 3-4. 


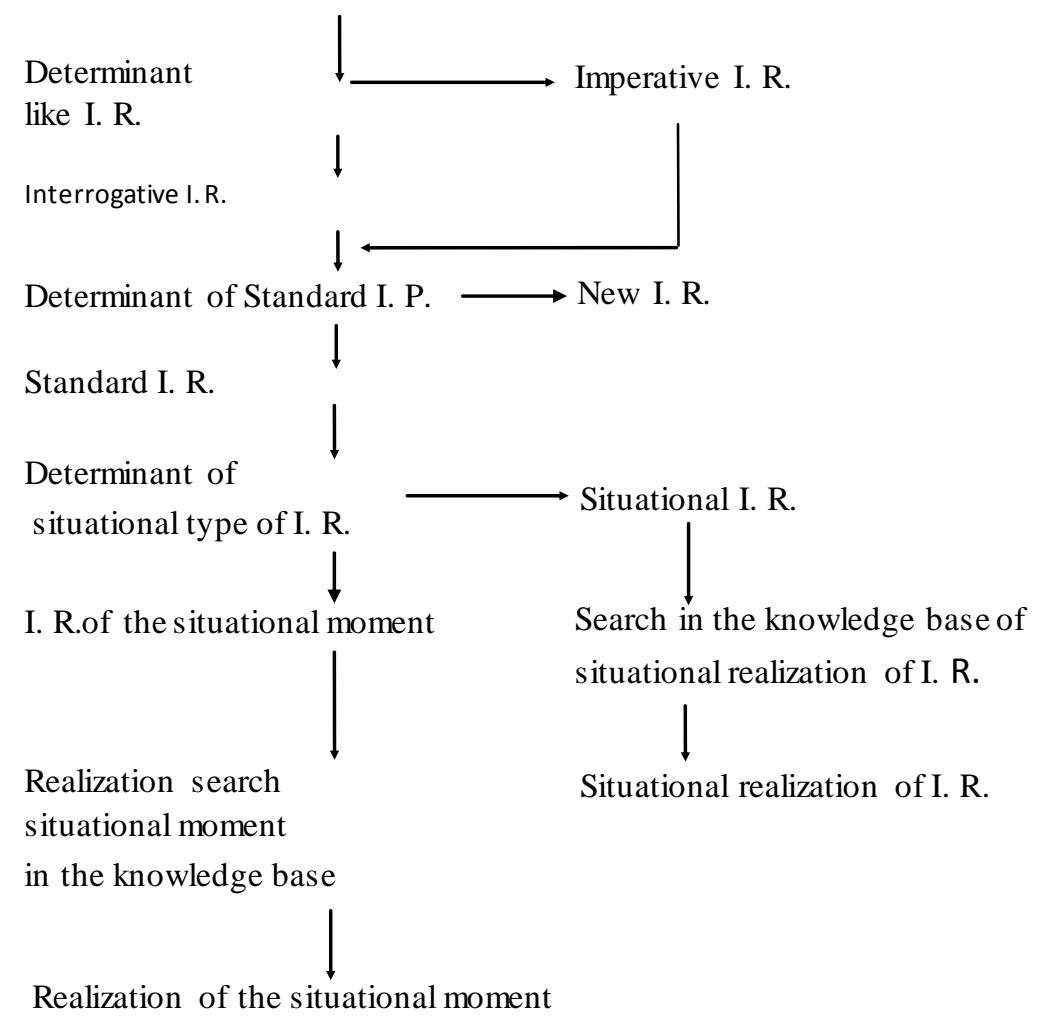

Figure 3. Realization of Standard Information Requirement (I. R.)

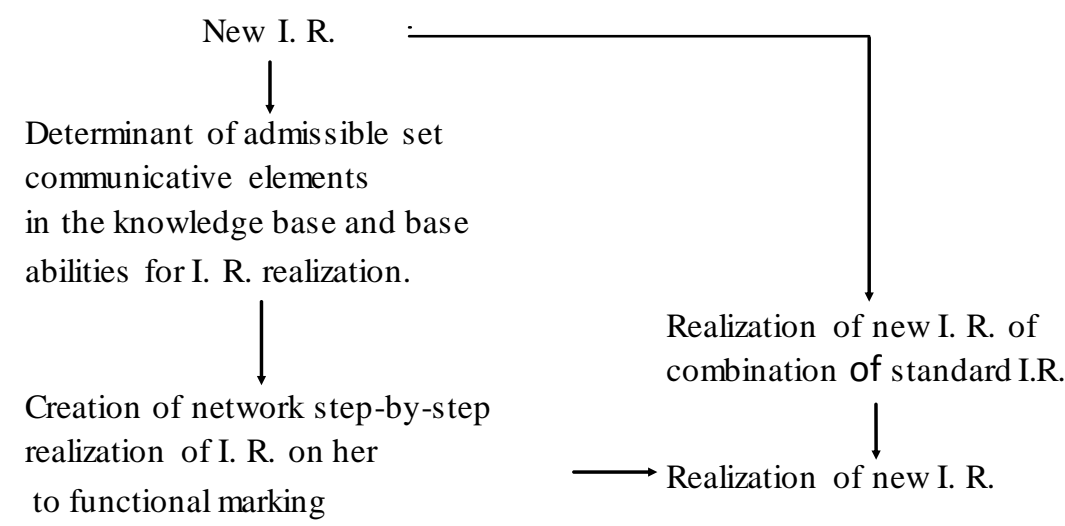

Figure 4. Realization of New Information Requirement (I. R.)

Retraining system is used to work with the new concepts (Figure 5) [4]. After implementation, the new information need is entered into the knowledge base and associated with the knowledge element, which is its implementation. The variation of such information needs is carried out in a variable part, which are implemented by standard procedures common to them.

The realization of combined information needs is developed by the investment, variation and combination of implementations of information needs, which are located in the knowledge base of the system. New information needs are built either by sequentially merging existing needs from implementations, by investing one in another, or by merging and investing at the same time. 


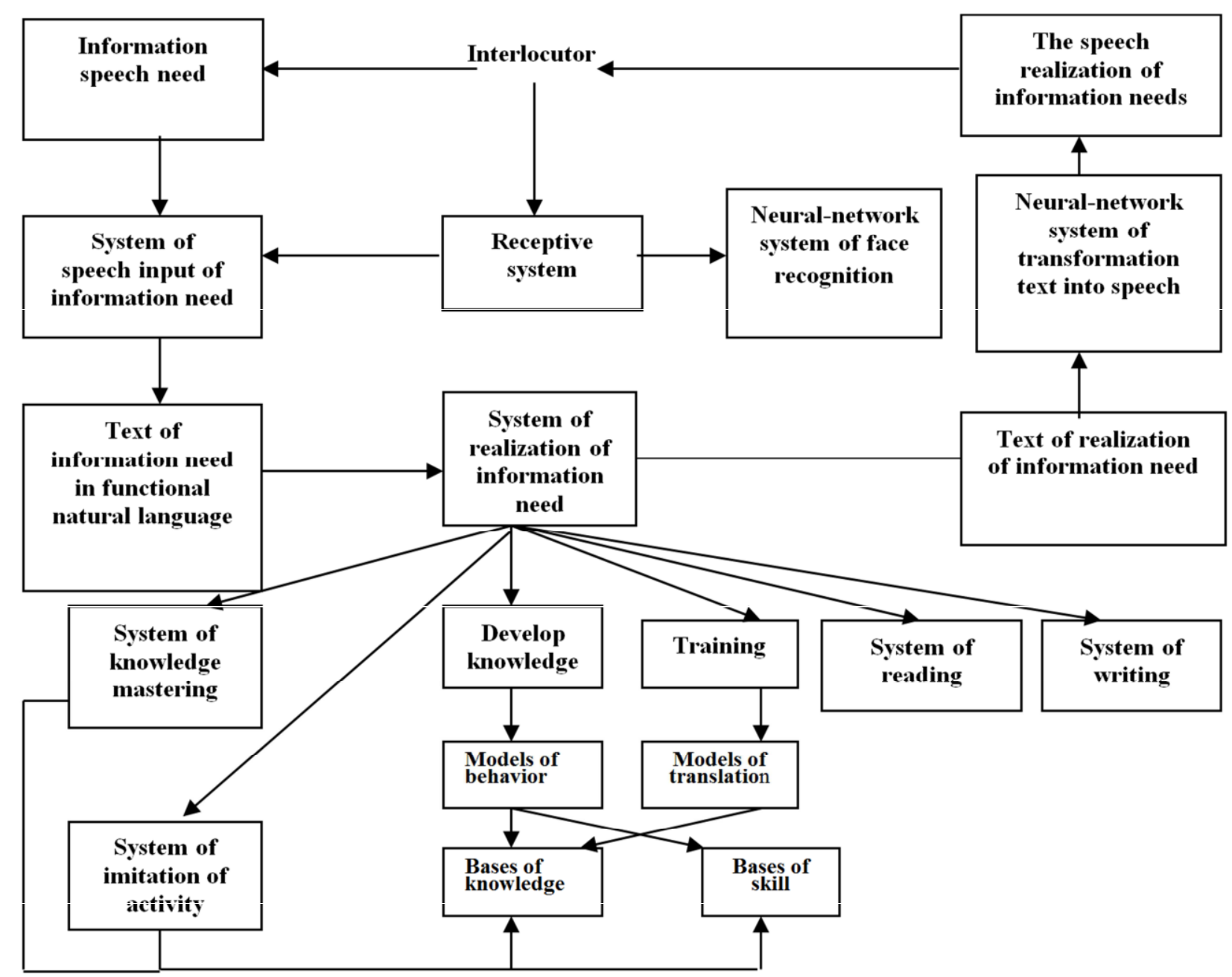

Figure 5. Retraining System

\section{Discussion}

\subsection{Cognitive Ensembles of Diversified Agents}

The digital transformation of the high-tech industry and social sphere now requires rapid reactions, diversification and flexible mobility. Mobile diversifiable collaboration agents are beginning to demonstrate the ability to work together effectively. Cognitive ensembles of mobile diversifiable agents use information from technology platforms such as Future Manufacturing Technologies European Technology Platform and analytical platforms such as Visiology, which allows you to quickly and efficiently solve the tasks of collecting, analyzing and visualizing large amounts of data. Rapid, efficient collection and analysis of large amounts of data, flexible online mobility of data updates, and a synergistic open collaboration of mobile diversifiable agents with information platforms and analytical systems will help accelerate the digital transformation of the high-tech industry and social sphere by training new skills. New skills can be learned in a virtual space and then developed in a specific environment. The accumulated experience of professional activity in the virtual space is used by cognitive ensembles of mobile diversified agents for the development of smart artificial intelligence.

Cognitive ensembles of agents are an actively developing direction of artificial intelligence, which is still in the formative stage. Work in the field of cognitive ensembles requires attracting knowledge and technology from a number of areas that were previously out of sight of artificial intelligence specialists. The synergy of cognitive ensembles, technological platforms and analytical systems brings a number of fundamentally new properties and capabilities to the formation of a cognitive virtual smart artificial intelligence, 
and essentially represents a qualitatively new, higher level of its development, the level that allows us to predict its leading position in the coming decades. Specialists in the field of artificial intelligence have a leading role here. This direction is a new interdisciplinary science of smart artificial intelligence, in which new systemic qualities and technological singularity arise in the process of joint action and mutual adaptation [5-11].

\subsection{Standard Case Application of Ensemble of Intelligent Interoperable Agents}

Standard case Application of ensemble of intelligent interoperable agents defines parameters, characteristics, methods, and other attributes of intelligent virtual agent interaction (Table 1 - Table 7). Intelligent virtual agent interaction uses categorical method of utility and preference [12].

Table 1. General

\begin{tabular}{|c|c|c|}
\hline Use case name & \multicolumn{2}{|c|}{ Application of ensemble of intelligent interoperable agents } \\
\hline Application domain & \multicolumn{2}{|c|}{ Hi-Tech Labor Market } \\
\hline Deployment model & \multicolumn{2}{|c|}{ Human digital double } \\
\hline Status & \multicolumn{2}{|c|}{ Results of research: Strong Artificial Distributed Intelligence } \\
\hline Scope & \multicolumn{2}{|c|}{ Economic and technical sectors and social services } \\
\hline Objective(s) & \multicolumn{2}{|c|}{$\begin{array}{l}\text { Find accurate and universal application of strong artificial distributed } \\
\text { intelligence }\end{array}$} \\
\hline & $\begin{array}{l}\text { Short description } \\
\text { (not more than } \\
150 \text { words) }\end{array}$ & $\begin{array}{l}\text { Ensemble is complex of intelligent interoperable agents } \\
\text { interacting through smart interface, implementing either } \\
\text { technological process, social services, multi-inter- trans- } \\
\text { disciplinary research, or production cycle. }\end{array}$ \\
\hline Narrative & $\begin{array}{l}\text { Complete } \\
\text { description }\end{array}$ & $\begin{array}{l}\text { Ensemble is complex of intelligent interoperable agents } \\
\text { interacting through smart interface, implementing either } \\
\text { technological process, social services, multi-inter- trans- } \\
\text { disciplinary research, or production cycle. In the creative } \\
\text { ensemble, the whole range of tasks by certain rules is } \\
\text { distributed among all agents. Job allocation means } \\
\text { assigning each agent a role whose complexity is } \\
\text { determined by the agent's capabilities. To organize the } \\
\text { task distribution process, the creative ensemble creates } \\
\text { either a distributed problem solution system or } \\
\text { decentralized artificial intelligence. In the first version, the } \\
\text { process of decomposition of the global problem and the } \\
\text { inverse process of composition of the found solutions } \\
\text { takes place under the control of some single "center." At } \\
\text { the same time, the creative ensemble is designed strictly } \\
\text { from top to bottom, based on the roles defined for the } \\
\text { agents and the results of dividing the global task into } \\
\text { subtasks. In the case of decentralized artificial } \\
\text { intelligence, task distribution occurs during agent } \\
\text { interaction and is synergistic. }\end{array}$ \\
\hline Stakeholders & \multicolumn{2}{|c|}{ Highly technological producer } \\
\hline
\end{tabular}




\begin{tabular}{|c|c|c|c|c|}
\hline $\begin{array}{l}\text { Stakeholders' } \\
\text { assets, values }\end{array}$ & \multicolumn{4}{|l|}{ Reputation } \\
\hline System's threats & \multicolumn{4}{|c|}{ Legal and ethical aspects of interaction with society. } \\
\hline \multirow{3}{*}{$\begin{array}{l}\text { Key performance } \\
\text { indicators (KPIs) }\end{array}$} & ID & Name & Description & $\begin{array}{c}\text { Reference } \\
\text { to } \\
\text { mentioned } \\
\text { use case } \\
\text { objectives }\end{array}$ \\
\hline & 1 & $\begin{array}{l}\text { AI management } \\
\text { of professional } \\
\text { cooperation } \\
\text { process }\end{array}$ & $\begin{array}{l}\text { The technology of } \\
\text { creative processes } \\
\text { control can itself predict } \\
\text { optimal terms of } \\
\text { execution of certain } \\
\text { stages on the basis of } \\
\text { accumulated information } \\
\text { about their labour } \\
\text { intensity, selection of } \\
\text { the route of staff load } \\
\text { and competences of } \\
\text { employees. Optimize } \\
\text { processes during their } \\
\text { execution - automatic } \\
\text { delegation of tasks } \\
\text { taking into account the } \\
\text { load of employees and } \\
\text { their competences. }\end{array}$ & $\begin{array}{l}\text { Improve } \\
\text { accuracy }\end{array}$ \\
\hline & 2 & $\begin{array}{l}\text { Productivity and } \\
\text { quality AI }\end{array}$ & $\begin{array}{l}\text { Strong artificial } \\
\text { intelligence works with } \\
\text { fewer mistakes and is } \\
\text { safer. Strong artificial } \\
\text { improves the quality of } \\
\text { life of man and society } \\
\text { in daily concerns, as } \\
\text { well as productivity in } \\
\text { high-tech industry and } \\
\text { production. }\end{array}$ & $\begin{array}{l}\text { Improve } \\
\text { efficiency }\end{array}$ \\
\hline \multirow{5}{*}{ AI features } & $\operatorname{Task}(\mathrm{s})$ & \multicolumn{3}{|c|}{$\begin{array}{l}\text { 1. Safe interaction of technocratic societies. } \\
2 \text {.Building high-tech synergies of technocratic societies. }\end{array}$} \\
\hline & Method(s) & \multicolumn{3}{|c|}{ Criterion method of utility and preference } \\
\hline & Hardware & \multicolumn{3}{|c|}{$\begin{array}{lllll}\text { Supercomputer } & \text { with } & \text { Strong } & \text { Artificial } & \text { Distributed } \\
\text { Intelligence } & & & & \end{array}$} \\
\hline & Topology & \multicolumn{3}{|c|}{ Distributed Modular Interconnect Topology } \\
\hline & $\begin{array}{l}\text { Terms and } \\
\text { concepts used }\end{array}$ & \multicolumn{3}{|c|}{$\begin{array}{l}\text { technocratic societies, high-tech synergies, intelligent } \\
\text { interoperable agents, utility and preference criteria. }\end{array}$} \\
\hline
\end{tabular}




\begin{tabular}{|l|l|l|}
\cline { 2 - 3 } $\begin{array}{l}\text { Standardization } \\
\text { opportunities/ } \\
\text { requirements }\end{array}$ & $\begin{array}{l}\text { Strong artificial distributed intelligence requires process standardization, as } \\
\text { does every human activity. }\end{array}$ \\
\hline $\begin{array}{l}\text { Challenges and } \\
\text { issues }\end{array}$ & Qualitatively new type of thinking not available to humans. \\
\hline \multirow{2}{*}{ Societal } & Description & Security and ethical and legal aspects \\
\cline { 2 - 3 } & $\begin{array}{l}\text { SDGs to be } \\
\text { achieved }\end{array}$ & $\begin{array}{l}\text { Universal approach to big data processing with smart } \\
\text { cognitive systems }\end{array}$ \\
\hline
\end{tabular}

Table 2. Data

\begin{tabular}{|l|l|}
\hline \multicolumn{2}{|c|}{ Data characteristics } \\
\hline Description & Strong Artificial Distributed Intelligence Data \\
\hline Source & Model and technology of Strong Artificial Distributed Intelligence \\
\hline Type & Strong \\
\hline Volume (size) & Hi-Tech Labor Market \\
\hline $\begin{array}{l}\text { Velocity (e.g. real } \\
\text { time) }\end{array}$ & Supercomputering Velocity \\
\hline $\begin{array}{l}\text { Variety (multiple } \\
\text { datasets) }\end{array}$ & streams of multiple datasets \\
\hline $\begin{array}{l}\text { Variability } \\
\text { (rate of change) }\end{array}$ & Retraining \\
\hline Quality & High \\
\hline
\end{tabular}

Table 3. Process Scenario

\begin{tabular}{|l|l|l|l|l|l|}
\hline \multicolumn{5}{|c|}{ Scenario conditions } \\
\hline N. & Scenario name & \multicolumn{1}{|c|}{ Scenario description } & Triggering event & Pre-condition & \multicolumn{1}{|c|}{$\begin{array}{c}\text { Post- } \\
\text { condition }\end{array}$} \\
\hline 1 & Training & $\begin{array}{l}\text { Train a model (deep neural } \\
\text { network) with training data } \\
\text { set }\end{array}$ & $\begin{array}{l}\text { Technological } \\
\text { process raw data } \\
\text { set is ready }\end{array}$ & $\begin{array}{l}\text { Formatting of } \\
\text { data }\end{array}$ & $\begin{array}{l}\text { Management } \\
\text { of safety }\end{array}$ \\
\hline 2 & Evaluation & $\begin{array}{l}\text { Expansion of the trained } \\
\text { model }\end{array}$ & $\begin{array}{l}\text { Development of } \\
\text { technological } \\
\text { thinking and } \\
\text { behaviour }\end{array}$ & $\begin{array}{l}\text { Cognitive } \\
\text { thinking } \\
\text { patterns and } \\
\text { psychologica }\end{array}$ & $\begin{array}{l}\text { Meeting KPI } \\
\text { requirements } \\
\text { is condition } \\
\text { of } \\
\text { development }\end{array}$ \\
\hline
\end{tabular}




\begin{tabular}{|l|l|l|l|l|l|} 
& & & 1 behaviors & \\
\hline 3 & Execution & $\begin{array}{l}\text { Model and Technology } \\
\text { Tooling }\end{array}$ & Interaction & $\begin{array}{l}\text { Activization } \\
\text { of Model }\end{array}$ & $\begin{array}{l}\text { Completion } \\
\text { of interaction }\end{array}$ \\
\hline 4 & Retraining & $\begin{array}{l}\text { Retrain a model with training } \\
\text { data set }\end{array}$ & $\begin{array}{l}\text { Certain period of } \\
\text { time has passed } \\
\text { since the last } \\
\text { training/ } \\
\text { retraining }\end{array}$ & $\begin{array}{l}\text { Additional } \\
\text { data and } \\
\text { knowledge }\end{array}$ & $\begin{array}{l}\text { Combining } \\
\text { Data and } \\
\text { Knowledge }\end{array}$ \\
\hline
\end{tabular}

Table 4. Training.

\begin{tabular}{|c|l|l|l|l|l|}
\hline Scenario name & \multicolumn{4}{|l|}{ Training } & \multicolumn{1}{|l|}{ Name of } \\
Step No. & Event & Primary actor & $\begin{array}{l}\text { Description of } \\
\text { process/activity }\end{array}$ & Requirement \\
\hline 1 & $\begin{array}{l}\text { Sample raw } \\
\text { data set is } \\
\text { ready }\end{array}$ & $\begin{array}{l}\text { Specification } \\
\text { and } \\
\text { classification }\end{array}$ & Manufacturer & $\begin{array}{l}\text { Transform sample } \\
\text { raw data }\end{array}$ & $\begin{array}{l}\text { Distributed } \\
\text { AI Software }\end{array}$ \\
\hline 3 & $\begin{array}{l}\text { Completion } \\
\text { of Step 1 }\end{array}$ & $\begin{array}{l}\text { Creating Set of } \\
\text { Experimental }\end{array}$ & Manufacturer & $\begin{array}{l}\text { Det of } \\
\text { experimental data } \\
\text { through job } \\
\text { modelling }\end{array}$ & $\begin{array}{l}\text { Software of } \\
\text { modelling }\end{array}$ \\
\hline & $\begin{array}{l}\text { Completion } \\
\text { of Step 2 }\end{array}$ & Model training & $\begin{array}{l}\text { AI solution } \\
\text { provider }\end{array}$ & $\begin{array}{l}\text { Train a model } \\
\text { neep neural } \\
\text { network) with } \\
\text { experimental data } \\
\text { set created by } \\
\text { Step 2 }\end{array}$ & Big SD \\
\hline
\end{tabular}

Table 5. Evaluation

\begin{tabular}{|c|c|c|c|c|c|}
\hline Scenario & \multicolumn{5}{|l|}{ Evaluation } \\
\hline Step No. & Event & $\begin{array}{c}\text { Name of } \\
\text { process/Activity }\end{array}$ & Primary actor & $\begin{array}{l}\text { Description of } \\
\text { process/activity }\end{array}$ & Requirement \\
\hline 1 & $\begin{array}{l}\text { Completion of } \\
\text { training/retraining }\end{array}$ & Research & Manufacturer & $\begin{array}{l}\text { Train model (deep } \\
\text { neural network) } \\
\text { with } \\
\text { experimental data } \\
\text { set created }\end{array}$ & Big SD \\
\hline 2 & $\begin{array}{l}\text { Completion of Step } \\
1\end{array}$ & Identification & $\begin{array}{l}\text { AI solution } \\
\text { provider }\end{array}$ & $\begin{array}{l}\text { Based on data, } \\
\text { detect execution } \\
\text { using a deep } \\
\text { neural network } \\
\text { trained in } \\
\text { learning scenario }\end{array}$ & Big SD \\
\hline 3 & $\begin{array}{l}\text { Completion of Step } \\
2\end{array}$ & Evaluation & Manufacturer & $\begin{array}{l}\text { Comparison of } \\
\text { phase } 2 \text { results } \\
\text { with human } \\
\text { performance }\end{array}$ & $\begin{array}{l}\text { Efficiency } \\
\text { and quality }\end{array}$ \\
\hline
\end{tabular}




\begin{tabular}{|l|l|}
\hline Input of evaluation & Productivity \\
\hline Output of evaluation & Efficiency and quality \\
\hline
\end{tabular}

Table 6. Execution.

\begin{tabular}{|c|c|c|c|c|c|}
\hline Scenario & Execution & & & & \\
\hline Step No. & Event & $\begin{array}{c}\text { Name of } \\
\text { process/Activity }\end{array}$ & Primary actor & $\begin{array}{l}\text { Description of } \\
\text { process/activity }\end{array}$ & Requirement \\
\hline 1 & $\begin{array}{l}\text { Completion of } \\
\text { comparison of } \\
\text { modeling } \\
\text { results with } \\
\text { human } \\
\text { performance }\end{array}$ & Research & Manufacturer & $\begin{array}{l}\text { Development of a } \\
\text { set of experimental } \\
\text { data through job } \\
\text { modelling }\end{array}$ & Quality \\
\hline 2 & $\begin{array}{l}\text { Completion of } \\
\text { Step } 1\end{array}$ & Identification & Manufacturer & $\begin{array}{l}\text { Based on modified } \\
\text { data train model } \\
\text { (deep neural } \\
\text { network) with } \\
\text { experimental data } \\
\text { set created }\end{array}$ & Compatibility \\
\hline \multicolumn{2}{|c|}{ Input of Execution } & \multicolumn{4}{|l|}{ Modification } \\
\hline \multicolumn{2}{|c|}{ Output of Execution } & \multicolumn{4}{|l|}{ Compatibility } \\
\hline
\end{tabular}

Table 7. Retraining

\begin{tabular}{|c|c|c|c|c|c|}
\hline $\begin{array}{l}\text { Scenario } \\
\text { name }\end{array}$ & \multicolumn{5}{|l|}{ Retraining } \\
\hline Step No. & Event & $\begin{array}{l}\text { Name of } \\
\text { process/ } \\
\text { Activity }\end{array}$ & Primary actor & $\begin{array}{l}\text { Description of } \\
\text { process/activity }\end{array}$ & Requirement \\
\hline 1 & $\begin{array}{l}\text { Certain period of } \\
\text { time has passed since } \\
\text { the last } \\
\text { training/retraining }\end{array}$ & Research & Manufacturer & $\begin{array}{l}\text { Additional data and } \\
\text { knowledge }\end{array}$ & Completeness \\
\hline 2 & Completion of Step 1 & $\begin{array}{l}\text { Experiment } \\
\text { al data set } \\
\text { creation }\end{array}$ & Manufacturer & $\begin{array}{l}\text { Combining Data and } \\
\text { Knowledge } \\
\text { Based on modified } \\
\text { data train model } \\
\text { (deep neural } \\
\text { network) with } \\
\text { experimental data set } \\
\text { created }\end{array}$ & Compatibility \\
\hline 3 & Completion of Step 2 & $\begin{array}{l}\text { Model } \\
\text { training }\end{array}$ & $\begin{array}{l}\text { AI solution } \\
\text { provider }\end{array}$ & $\begin{array}{l}\text { Comparison of phase } \\
2 \text { results with human } \\
\text { performance }\end{array}$ & $\begin{array}{l}\text { Efficiency and } \\
\text { quality }\end{array}$ \\
\hline \multicolumn{2}{|c|}{ Specification of retraining data } & \multicolumn{4}{|c|}{ Retraining data set has to include recent data } \\
\hline
\end{tabular}




\subsection{Developing the Mindfulness of Artificial Intelligence by Ensembles of Diversified Agents}

Cognitive ensembles of mobile diversifiable agents have a well-developed and replenished information model of the outside world due to the presence of BZ, mechanisms of reasoning and action analysis. Agent mobility is the ability to migrate across technology platforms in search of the necessary information with access to analytical systems for its analysis [13].

Cognitive ensembles contain a variety of mobile diversifiable agents distributed in cee, which migrate along it in search of relevant data, knowledge, procedures on technological platforms and analytical systems and are combined to achieve their goals. The cognitive behavior of the agent is ensured by the ability to take reevaluation. The architecture of the cognitive ensemble allows you to use self-learning agents, the knowledge of which is formed in the process of solving practical problems.

The interaction of agents establishes bilateral and multilateral dinami relations between the ensemble, technology platforms and analytical systems. It is a prerequisite for the formation of virtual communities. Interaction is accompanied by the mutual transformation of the agents themselves and the relations between them. The main characteristics of the interaction are the orientation, selectivity, intensity and dynamics:

- Direction - positive or negative; Coo operation or competition; cooperation or confrontation; coordination or subordination, etc.;

- Selectivity - interaction occurs between the agents, which in any way correspond to each other and the task set. In this case, the agents can be bound in one respect and independent in another;

- Intensity - interaction between agents does not result in presence or absence, but is characterized by a determined force;

- Dynamism - the direction of mutual action can change over time.

Analysis of interaction between agents includes the following tasks:

- Identification of the situation of interaction of agents;

- Allocation of the main roles and their distribution among agents;

- Determination of the number and types of interacting agents;

- Building a formal model of interaction;

- Identification of a set of possible strategies for the behavior of agents;

- Formation of many communicative actions.

Each agent has a limited set of knowledge it needs to achieve its own and common goals. Obligations are one of the tools to streamline the singular interactions of agents. They allow you to anticipate the behavior of other agents, predict the future and plan your own actions. The following groups of obligations can be distinguished: (a) obligations to other agents; b) the agent's obligations to the group; c) the group's obligations to the agent; d) obligation of the agent to himself. The formalized representation of goals, obligations, desires and intentions, as well as all other characteristics, forms the basis of the mental model of an intel mobile diversifiable agent that ensures its reasonable behavior.

There are different forms of interaction between agents:

- Simple cooperation, which involves the integration of the experience of individual agents (distribution of tasks, exchange of knowledge, etc.) without special measures to coordinate their actions;

- Coordinated cooperation where agents are forced to coordinate their actions (sometimes involving a special coordinating agent) in order to use resources and expertise effectively;

- Productive collaboration where agents share resources or solve a common problem by sharing experiences and not interfering with each other. 
A competition-based model is used as a reasonable model for coordinating agent behavior. In the process of collective work of mobile diversifiable agents, many tasks are solved:

- Recognition of the need for cooperation;

- Selection of suitable partners;

- The possibility of taking into account the interests of partners;

- Organization of negotiations on joint actions;

- Development of joint action plans;

- Synchronization of joint actions;

- Decomposition of tasks and division of duties;

- Identification of conflicting objectives;

- Competition for joint resources;

- Formation of rules of conduct in the team;

- Training in team behavior, etc.

A feature of the collective behavior of mobile diversified agents is that their interaction in the process of solving private problems (or one common one) gives rise to a new quality of solving these problems. To do this, mobile agents can leave the client server and move to the remote server to perform their actions, after which they can return. The use of mobile agents provides:

- Reduction of time and cost of data transmission;

- Extension of limited local resources;

- Facilitating coordination;

- Perform asynchronous calculations.

The life cycle model of mobile diversifiable agents includes the following stages:

- processing of new messages;

- Definition of rules of conduct;

- Execution of actions;

- Updating the mental model according to the specified rules;

- Planning of actions based on preferences and usefulness.

The mental model includes a description of the goals, preferences, utility, obligations and capabilities, as well as the rules of behavior of agents. On the basis of this model, the selection of certain actions of intelligent mobile diversifiable agents is carried out.

When using mobile agents, you have to solve a number of serious problems, including: the legality of ways to move agents across the network; Verification of agents (for example, protection against ins and outs) respect for private property rights; maintaining confidentiality of information; overpopulation of the agent network; compatibility of the agent code and the hardware and software of the network machine.

The main efforts to improve the mindfulness of intellectual mobile diversifiable search agents on the Internet are aimed at developing models for the presentation of knowledge, the mechanics of inference of new knowledge, models of reasoning and ways of training agents to ensure the full interaction of ensembles of mobile smart agents with technology platforms and analytical systems.

\subsection{Smart Artificial Intelligence Preferences}

Smart artificial intelligence achieves goals based on preferences. To identify a preference on a set of objects A, this means to indicate a set of all those pairs of objects $(a, b)$ for which the object $a$ is preferable to $b$. The following approaches are possible when a preference is identified.

1. Unconditional table-based approach.

We will fill in the table according to the principle:

aij $=1$ if the $\mathrm{i}$-th object is better than the $\mathrm{j}$-th object;

aij $=0$ if $\mathrm{i}$ object is worse than $\mathrm{j}$ object. 


\section{Logical Approach.}

The approach consists of three stages:

- Identify the specific criteria by which preferences are chosen;

- Table of "alternatives-private criteria" is drawn up, in which for each alternative the values of quantitative private criteria or the ranks of qualitative criteria are indicated;

- Selects a crucial rule to determine the best alternative.

Since the private criteria under consideration are qualitative, they are given not quantitative, but rank estimates (by preference). Rank scores can be considered as scores. On their basis, preference must be determined. To do this, a decisive rule is created. For example, $1,2,3$.

1. Absolute preference. Alternative ai is preferable to alternative aj, if by all particular criteria ai is preferable to or equivalent to aj. Absolute preference has a transitivity property (if $\mathrm{A}$ is preferred to $\mathrm{B}$ and $\mathrm{B}$ is preferred to $\mathrm{C}$, then $\mathrm{A}$ is preferred to $\mathrm{C}$ ).

2. Preference by majority rule. The alternative ai is better than aj if the number of private criteria by which ai is better than aj is more than the number of criteria by which ai is worse than aj.

3. The criterion of the largest sum of points. Instead of quantifying private criteria, you can place their rank values. The rank value is considered as a point score, with the lowest score being set for the worst value - 1 , and the highest score for the best value. Then the preference criterion is formulated as follows: the alternative ai is better than the alternative aj if the sum of the points for ai is greater than for aj.

When using preference criteria according to the majority rule or the sum of points ratings, an additional requirement is often imposed on the alternative - the absence of a private criterion with the worst value. Such alternatives are immediately excluded from consideration.

With a large number of alternatives and private criteria, directly determining the best alternative according to the majority criterion becomes difficult due to the difficulty of calculating the number of best and worst criteria for each alternative. In this case, a preference table should be drawn up to highlight the best alternative.

According to the rule of majority and absence of the worst value, a table of preferences for alternatives is compiled: if alternative $b$ is preferable $a$, then at the intersection of row $b$ and column a it is set to 1 , otherwise 0 .

\subsection{Useful Choice of Smart Artificial Intelligence}

A useful choice of smart artificial intelligence is a functional that determines preferences on a certain set of possibilities according to the criterion of utility. Smart artificial intelligence develops the ability to distinguish the properties and functions of entities, regardless of the various conditions in which they are observed, based on useful choices. The better he begins to distinguish analogies with other related entities, the sooner he acquires the ability to generalize. The logical method, as a practical technique for using logical laws and rules in a specific type of activity of smart artificial intelligence, turns them into an algorithm for logical rational thinking. When using logical techniques, it turns general logic into application logic. To do this, it forms a set of reasonable capabilities: situations that can arise in a virtual application environment. It also forms a set of spawns - the execution of rules and operations in a virtual application environment. And it forms a set of cognitive functions that can solve the problem of moving from the starting situation to the target situation. The trajectory of progress to the target state is built according to the rules and operations of births in the applied virtual environment with cognitive functions, using methods of analogy, similarity, a combination of available solutions and increased sensitivity of artificial intelligence. By this method of intellectual activity, intelligent artificial intelligence establishes reasonable purposeful sequences, forming new knowledge in the mental model through analysis, synthesis, analogy, comparison, induction, deduction and creative 
ensembles from well-trained artificial network models to achieve the desired goal in dialogue with a professional expert [14-16].

\section{Conclusion}

Smart artificial intelligence technology systems will consist of many smart components, such as visual detection subsystems, environmental perception, reasoning and decision making, and other smart subsystems. Recommendation systems have already become widespread in a variety of business domains. For some companies, they are the core of business, for example, in classic recommendation services (TripAdvisor), for others, they perform a service function designed to improve the quality of customer service or make content more convenient. It is possible to make the recommendation system more "human," and the mention of the reasons for the found recommendation when it is shown carries additional argumentation and makes it convincing that it benefits the recipient and increases conversion to the target action. The direction of automatic rule creation is already applied in the area of decision systems. Smart systems with artificial intelligence for air quality control quickly respond to incidents and complaints of residents, respond to improvements in the environmental situation. Improving air quality has a positive impact on the health of citizens and increases life expectancy. Large factories in Japan are gradually equipping engineers with Microsoft Hololens headsets, the business segment uses AR for the online presence of augmented reality, stereo speakers create feelings that resemble conversation in real life.. Musashi Seimitsu Industry, a major automotive parts manufacturer and one of Honda Motor's main suppliers, uses Hololens at a plant in Mexico. In order not to spend time and money on transportation of engineers, the company introduces AR headsets to factories around the world and is engaged in training new jobs in augmented reality.

To combine smart subsystems in a technological system with smart artificial intelligence, their standardization is carried out. In the future, a reliable and safe viable smart artificial intelligence will significantly change the life of the highly technological digital community.

\section{References}

[1] Evgeniy Bryndin. Practical Development of Creative Life-Saving Strong Artificial Intelligence. Communications, Vol.7, No.1, 2019. Pages: 31-39.

[2] Stewart Russell, Peter Norvig. Artificial Intelligence: Modern Approach. Williams, 2019. 1408 p. ISBN: 978-5-8459-1968-7

[3] Wu Jun. Research on the Framework of Smart City Operating System Based on New ICTs. American Journal of Artificial Intelligence. Volume 4, Issue 1, June 2020, Pages: 36-41. doi: 10.11648/j.ajai.20200401.14

[4] Evgeniy Bryndin. System retraining to professional competences of cognitive robots on basis of communicative associative logic of technological thinking. International Robotics Automation Journal. 2019; 5(3.):112-119.

[5] Evgeniy Bryndin. Human Digital Doubles with Technological Cognitive Thinking and Adaptive Behaviour. Software Engineering, Volume 7, Issue 1, 2019. P. 1-9.

[6] CRONEMBERGER F, GIL-GARCIA J R. Big data and analytics as strategies to generate public value in smart cities: proposing an integrative framework [M]. Switzerland: Springer Nature, 2019.

[7] Evgeniy Bryndin. Development of Artificial Intelligence by Ensembles of Virtual Agents on Technological Platforms. COJ Technical \& Scientific Research.2(4). 2020. Pages: $1-8$. 
[8]. Evgeniy Bryndin. Development of artificial intelligence by ensembles of virtual diversification agents. International Journal of Research in Engineering. Volume 2; Issue 1; 2020; Page 08-14.

[9] Raja Muhammad Asif Zahoor, Khan, Junaid Ali, Qureshi I. M. (2019) Evolutionary Computational Intelligence in Solving the Fractional Differential Equations. 11th Asian Conference, ACIIDS 2019, Yogyakarta, Indonesia, April 8-11, 2019, Proceedings, Part I, 231-240.

[10] Evgeniy Bryndin. Development of Artificial Intelligence by Ensembles of Virtual Agents with Mobile Interaction. Automation, Control and Intelligent Systems. Volume 8; Issue 1. 2020. Pages: 1-8.

[11] Oleg Vasylovych Moroz, Model of Self-organizing Knowledge Representation and Organizational Knowledge Transformation, American Journal of Artificial Intelligence. Vol. 4, No. 1, 2020, pp. 1-19. doi: 10.11648/j.ajai.20200401.11

[12] ISO/IEC JTC 1/SC 42/WG 4 Use cases and applications Convenorship: JISC (Japan). 2019-12-23. https://isotc.iso.org/livelink/livelink/open/jtc1sc42 wg4

[13] Evgeniy Bryndin. Standardization of Artificial Intelligence for the Development and Use of Intelligent Systems. Advances in Wireless Communications and Networks. Volume 6, ,Issue 1, 2020, pp. 1-9.

[14] Evgeniy Bryndin. Safe Interaction of Technocratic Societies Through Standardy Ensemble of Intellectual Virtual Agents. Control Science and Engineering. Vol. 4, Issue 1, 2020, pp. 8-15.

[15] Evgeniy Bryndin. Collaboration Robots with Artificial Intelligence (AI) as Digital Doubles of Person for Communication in Public Life and Space. Budapest International Research in Exact Sciences (BirEx-Journal), Volume 1, No. 4, 2019. Pages: 1-11.

[16]. Evgeniy Bryndin. Formation of Technological Cognitive Reason with Artificial Intelligence in Virtual Space. Britain International of Exact Sciences Journal, Volume 2, Issue 2, May 2020. Page: 450-461. 